\title{
Acute respiratory distress following intravenous injection of an oil-steroid solution
}

\author{
Michael Russell MD PhD ${ }^{1}$, Aric Storck MD², Martha Ainslie $M D^{3}$
}

\begin{abstract}
M Russell, A Storck, M Ainslie. Acute respiratory distress following intravenous injection of an oil-steroid solution. Can Respir J 2011;18(4):e59-e61.

A case of acute respiratory distress and hypoxemia following accidental intravenous injection of an oil-steroid solution in a body builder is presented. Chest roentography at the time of presentation showed diffuse bilateral opacities, and computed tomography revealed predominantly peripheral ground-glass opacifications. The patient's symptoms gradually improved over $48 \mathrm{~h}$ and imaging of the chest was unremarkable one week later. The pathophysiology, diagnosis and treatment of this rare but potentially lifethreatening complication of intravenous oil injection are discussed.
\end{abstract}

Key Words: Pulmonary oil embolism; Steroid-oil injection

\section{Une détresse respiratoire aiguë après l'injection intraveineuse d'une solution d'huile de stéroïdes}

\begin{abstract}
Est exposé le cas d'un culturiste qui a souffert d'une détresse respiratoire aiguë et d'une hypoxémie après l'injection intraveineuse accidentelle d'une solution d'huile de stéroïdes. La radiographie pulmonaire à la présentation a révélé des opacités bilatérales diffuses, et la tomodensitométrie, des opacifications périphériques en verre dépoli. En 48 heures, les symptômes du patient se sont graduellement résorbés, et l'imagerie des poumons ne révélait plus rien d'exceptionnel une semaine plus tard. Les auteurs présentent la physiopathologie, le diagnostic et le traitement de cette complication rare causée par l'injection d'huile par voie intraveineuse et qui peut mettre en jeu le pronostic vital.
\end{abstract}

\section{CASE PRESENTATION}

A previously healthy 21-year-old man presented to the emergency department with acute onset dyspnea approximately $24 \mathrm{~h}$ following self-administered injection of an oil-steroid solution into his right buttock. The patient admitted to a single injection of a mixture of anabolic steroids suspended in oil, including commercially available preparations of testosterone enanthate and boldenone undecylenate. At the time of injection, he aspirated blood before administering the anabolic steroid, then repositioned but did not withdraw the needle. Within 1 min of injection, he developed transient shortness of breath that resolved initially but subsequently recurred and progressed to the point he presented to the emergency department $24 \mathrm{~h}$ later.

Medical history was significant for a previous emergency room assessment for acute respiratory distress, at which time pulmonary embolus was ruled out with a computed tomography (CT)-pulmonary embolism protocol. The patient was a nonsmoker, and denied recreational or intravenous drug use, significant alcohol use or any recent unusual inhalation exposures. He was self-employed as a tattoo and graphic design artist. The patient indicated that he had been sexually active with multiple partners over the previous year and had tested negative for both HIV and hepatitis $\mathrm{C}$ virus within the year before presentation.

The patient was hypoxic at rest, with oxygen saturations of $88 \%$ to $92 \%$ on peripheral pulse oximetry, and experienced significant desaturation to $82 \%$ to $85 \%$ with minimal activity. Heart rate, blood pressure and temperature were within normal limits. A physical examination revealed a fit man of average height and weight with a muscular build. The patient's work of breathing was normal when stationary, but he rapidly became tachypneic on exertion. Lung auscultation revealed decreased breath sounds in the lower lung fields, with coarse crepitations and faint expiratory wheezing bilaterally, as well as a mildly prolonged expiratory phase. The remainder of the physical examination was unremarkable, notably including an absence of petechial rash and a grossly normal neurological examination.

Complete blood count plus differential, serum electrolytes and coagulation studies were within normal limits. D-dimer was elevated at $1.43 \mathrm{mg} / \mathrm{L}$ (upper limit of normal for reference range $0.51 \mathrm{mg} / \mathrm{L}$ ). An electrocardiogram and urinalysis were unremarkable. Arterial blood drawn in the emergency department for gas analysis on room air dem-

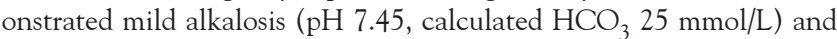
significant hypoxemia (arterial $\mathrm{PO}_{2} 54 \mathrm{mmHg}$ ) with no evidence of hypercapnia (arterial $\mathrm{PCO}_{2} 36 \mathrm{mmHg}$ ).

A chest $\mathrm{x}$-ray taken at the time of initial assessment showed diffuse bilateral opacities (Figure 1A) and CT-pulmonary embolism of the thorax revealed multifocal regions of ground-glass opacification in a predominantly peripheral distribution throughout the lungs, but no evidence of pulmonary embolus (Figure 1B). The patient was admitted with a working diagnosis of pulmonary oil embolism and started on supplemental oxygen therapy at $2 \mathrm{~L} / \mathrm{min}$ via nasal cannula.

\section{DISCUSSION}

The present report is the first to describe a case of pulmonary oil embolism following accidental intravascular injection of an oil-steroid solution. Acute lung injury and respiratory distress following intravascular introduction of oil is uncommon and has only been described in a small number of case reports (1-6). The pathophysiology underlying this phenomenon is postulated to be similar to that observed with the more extensively studied fat embolism syndrome (FES). Although the precise mechanism by which intravascularization of lipid emboli leads to the clinical features of FES has yet to be completely described, two theories have been proposed to explain the pulmonary dysfunction that occurs.

The mechanical theory postulates that fat emboli become physiologically lodged in the pulmonary capillaries, resulting in a ventilationperfusion mismatch. Alternatively, the biochemical theory suggests that hormonal changes induce the systemic release of free fatty acids that are toxic to pneumocytes and the capillary endothelium of the lung, causing interstitial hemorrhage, edema and chemical pneumonitis (7). A symptom-free period precedes the development of clinical features, suggesting that the formation of toxic biochemicals is necessary for the clinical syndrome to develop. The mechanical and biochemical theories are not mutually exclusive and the clinical picture associated with pulmonary oil embolism likely results from several physiological processes.

${ }^{1}$ Department of Medicine, Internal Medicine Residency Program, University of Calgary, Foothills Medical Centre; ${ }^{2}$ Department of Emergency Medicine, Foothills Medical Centre, Calgary, Alberta; ${ }^{3}$ Division of Respirology, Department of Internal Medicine, University of Manitoba, Health Sciences Centre, Winnipeg, Manitoba

Correspondence: Dr Michael Russell, Department of Medicine, Internal Medicine Residency Program, University of Calgary, Foothills Medical Centre, 4919 Viceroy Drive Northwest, Calgary, Alberta T3A OV2. Telephone 403-284-3679, fax 403-944-1666, e-mail michael.russell@albertahealthservices.ca 

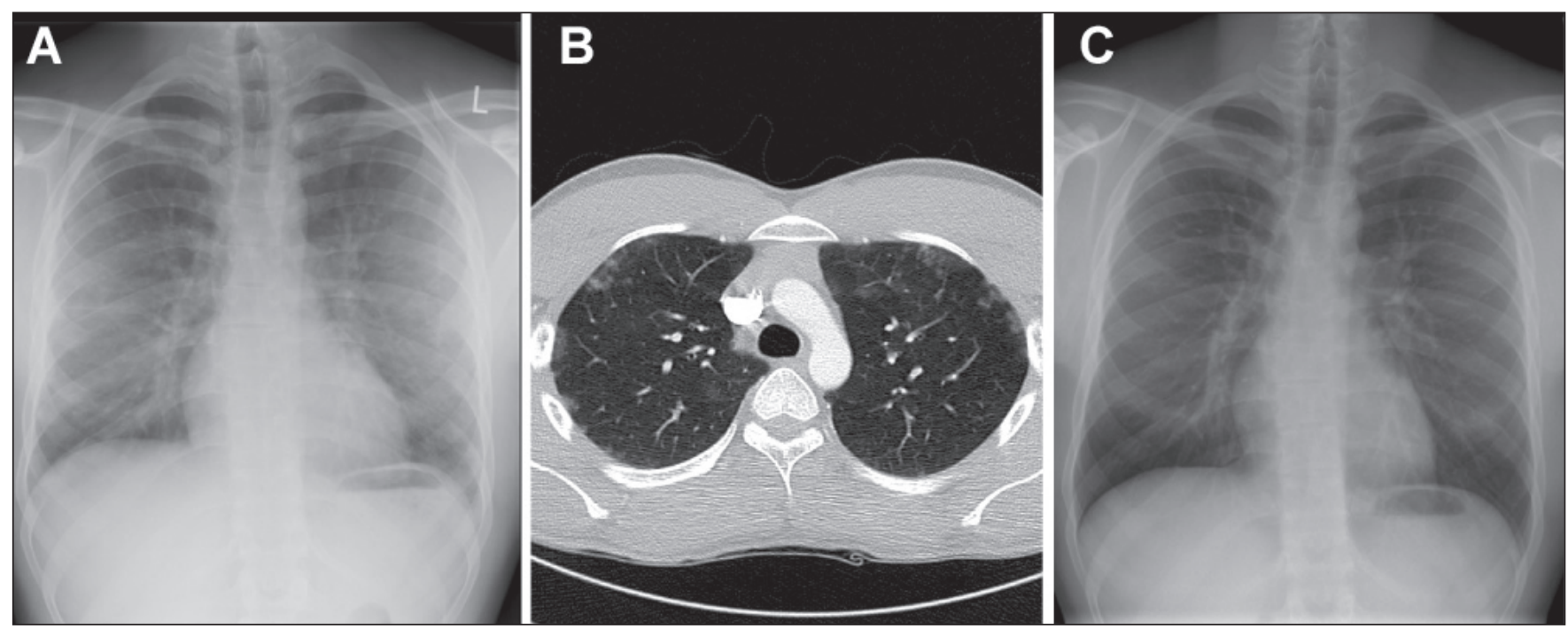

Figure 1) A Chest radiograph showing diffuse opacification and increased vascular markings bilaterally. B Axial slice from computed tomography scan of the thorax demonstrating discrete ground-glass opacities bilaterally in a peripheral predominant distribution. C Chest radiograph taken one week after discharge demonstrating radiographic resolution of diffuse bilateral opacities

FES is characterized by an initial asymptomatic latent period following introduction of lipid emboli into the systemic circulation, with subsequent development of ventilation-perfusion mismatch and toxic insult to pneumocytes and capillary endothelial cells resulting in dyspnea, tachypnea and hypoxia within $12 \mathrm{~h}$ to $72 \mathrm{~h}$ after lipid embolization (7). The clinical presentation of FES is highly variable, ranging from asymptomatic to mild respiratory distress, hypoxia and nonproductive cough, to the life-threatening triad of FES consisting of respiratory difficulty, petechial hemorrhages and neurological changes. The classic triad of FES is relatively uncommon, occurring in only $3 \%$ to $4 \%$ of cases despite the relatively high incidence of fat emboli following long bone fractures (greater than 90\%) (8-10). The relatively low incidence of symptomatic events following intravascular introduction of lipid emboli suggests that the majority of cases of lipid embolization are not clinically relevant and go undetected.

Diagnosis of respiratory distress due to intravascular oil embolization can be challenging given the nonspecific nature of the symptoms and the latent period that often precedes symptom onset. Bronchoalveolar lavage to detect fat droplets in alveolar macrophages has been examined as a means to diagnose pulmonary fat emboli (11); however, the invasive nature of this procedure limits its utility as a diagnostic tool. Furthermore, no uniformly specific diagnostic imaging findings have been described to date. However, several case reports have identified patterns that may be suggestive of pulmonary lipid embolism in the appropriate clinical setting.

Kiyokawa et al (3) reported finding a combination of interstitial and alveolar patterns in a peripheral-predominant distribution on chest roentography in a case of acute lung injury following intentional injection of vegetable oil. The authors noted, however, that in most cases, chest $\mathrm{x}$-ray findings are normal. Arakawa et al (12) reviewed chest roentograms and CT scans of six patients with pulmonary FES, and found focal areas of consolidation and/or ground-glass opacities with a predominantly upper lobe distribution as well as diffuse ground-glass opacification in the majority of cases. Moreover, Malagari et al (8) described bilateral ground-glass opacities with a predominantly peripheral distribution on high-resolution CT imaging of the thorax in mild pulmonary FES. Although not diagnostic of fat embolism, these imaging patterns - similar to those observed in the present case - may be suggestive in the setting of a compatible history and physical findings. Although specific features on high-resolution CT imaging of the chest were reported in this case series, the diagnostic value of this imaging pattern in the setting of a highly variable clinical picture remains to be determined.
Treatment options in cases of suspected or confirmed pulmonary oil embolism have been largely limited to supportive care in previous reports of intravenous lipid injection (1-6). Chin et al (13) reported the successful treatment and subsequent resolution of one case of idiopathic lipoid pneumonia with oral prednisolone. However, we were unable to locate any other reports or controlled studies to validate the use of steroids as a therapeutic option in the treatment of pulmonary lipid emboli. Therefore, the best treatment at this time remains early diagnosis and introduction of supportive care measures.

\section{CONCLUSION}

In contrast to classic cases of FES, which are typically preceded by a symptom-free latent period, the patient described in the present report experienced an acute dyspneic reaction following introduction of oil into the blood stream. Similar reactions preceding the development of overt pulmonary lipiodol embolism have been described within $1 \mathrm{~h}$ of transcatheter arterial chemoembolization for hepatocellular carcinoma (14), suggesting that introduction of lipid droplets into the circulation can lead to rapid onset of respiratory distress. The injection of oil-steroid solution was unwitnessed in the present case and it was, therefore, difficult to discern whether the initial shortness of breath was truly respiratory difficulty due to arterial injection of oil or more a subjective experience related to the injection event itself.

The patient's condition improved dramatically over the $36 \mathrm{~h}$ following initial presentation, and he was subsequently discharged home with a resting oxygen saturation of $93 \%$, with desaturation to $90 \%$ on exertion. Chest $\mathrm{x}$-rays at the time of discharge and one week later (Figure 1C) were both unremarkable, with no evidence of the bilateral changes seen on the initial roentograms.

The present case illustrates the need for timely diagnosis of pulmonary oil embolism and institution of supportive care measures to limit the morbidity and mortality associated with this rare, but potentially life-threatening condition. A high index of suspicion is necessary to make an accurate diagnosis given the variability of clinical presentation and the relative paucity of specific findings on diagnostic imaging and laboratory testing results. However, in the setting of acute respiratory distress and a mechanism of injury suspicious for vascular introduction of lipid emboli, chest roentography and CT can be useful in prompting physicians to consider the possibility of pulmonary oil embolus as a diagnosis. 


\section{REFERENCES}

1. Bhagat R, Holmes IH, Kulaga A, Murphy F, Cockcroft DW. Self-injection with olive oil. A cause of lipoid pneumonia. Chest 1995;107:875-6.

2. Drent M, Cobben NA, Henderson RF, Jacobs JA, Wouters EF, van Dieijen-Visser MP. BAL fluid LDH activity and LDH isoenzyme pattern in lipoid pneumonia caused by an intravenous injection of lamp oil. Eur Respir J 1996;9:2416-8.

3. Kiyokawa H, Utsumi K, Minemura K, et al. Fat embolism syndrome caused by vegetable oil injection. Intern Med 1995;34:380-3.

4. Seifert SA, Dart RC, Kaplan EH. Accidental, intravenous infusion of a peanut oil-based medication. J Toxicol Clin Toxicol 1998;36:733-6.

5. Smazal SF Jr, Brown RCC. Pitfalls to avoid: Accidental intravenous injection of ethiodol. J Can Assoc Radiol 1979;30:170.

6. Uzun O, Findik S, Danaci M, Katar D, Erkan L. Pulmonary and cerebral oil embolism after hystersalpingography with oil soluble contrast medium. Respirology 2004;9:134-6.

7. Taviloglu K, Yanar H. Fat embolism syndrome. Surg Today 2007;37:5-8.
8. Malagari K, Economopolous N, Stoupis C, et al. High-resolution CT findings in mild pulmonary fat embolism. Chest 2003;123:1196-201.

9. Levy DL. The fat embolism syndrome: A review. Clin Orthop 1990;261:281-6.

10. Aoki N, Soma K, Shinedo M, et al. Evaluation of potential fat emboli during placement of intramedullary nails after orthopedic fractures. Chest 1998;3:178-81.

11. Georgopolous D, Bouros D. Fat embolism syndrome. Chest 2003;123:982-3.

12. Arakawa H, Kurihara Y, Nakajima Y. Pulmonary fat embolism syndrome: CT findings in six patients. J Comput Assist Tomogr 2000;24:24-9.

13. Chin NK, Hiu KP, Sinniah R, Chan TB. Idiopathic lipoid pneumonia in an adult treated with prednisolone. Chest 1994;105:956-7.

14. Wu G, Perng W, Chen C, Chian C, Peng C, Su W. Acute respiratory distress syndrome after transcatheter arterial chemoembolization of hepatocellular carcinomas. Am J Med Sci 2009;338:357-60. 


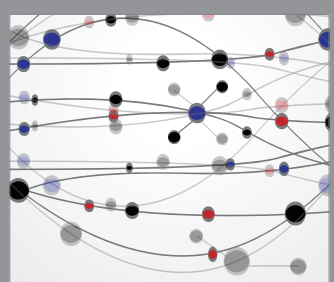

The Scientific World Journal
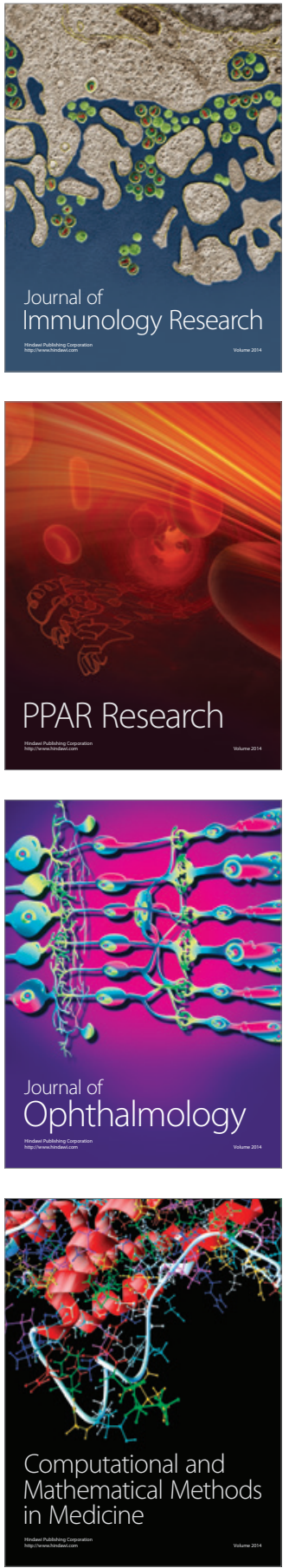

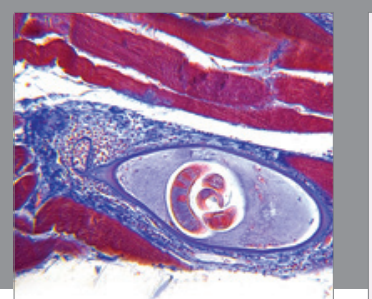

Gastroenterology Research and Practice

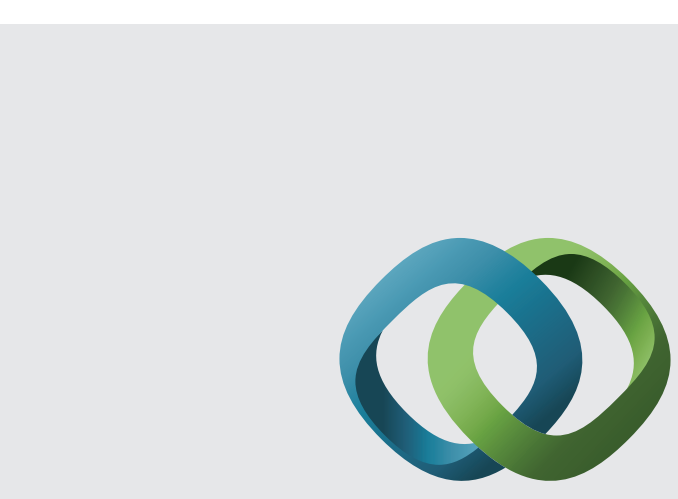

\section{Hindawi}

Submit your manuscripts at

http://www.hindawi.com
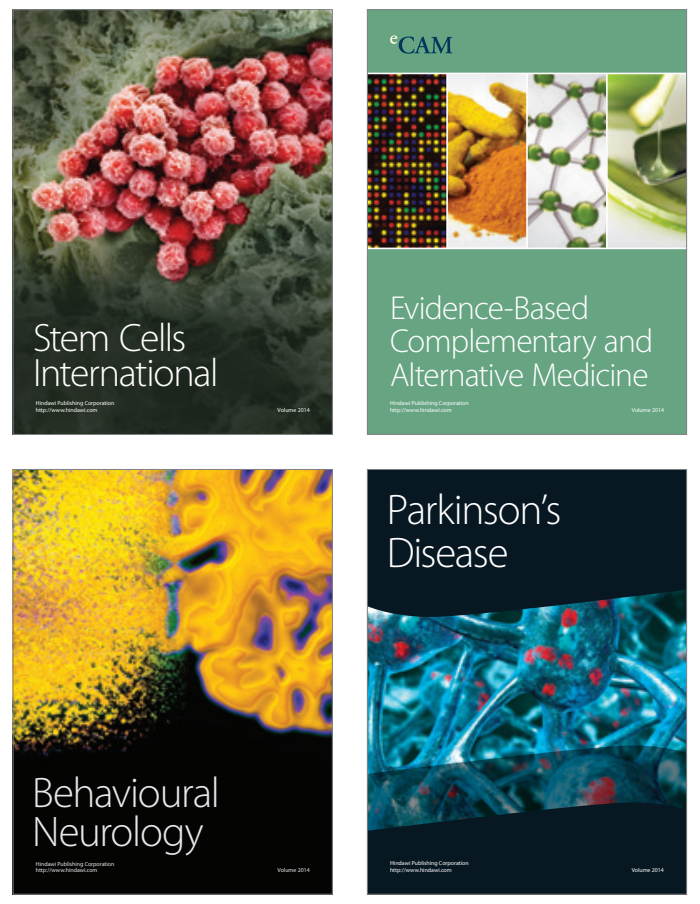
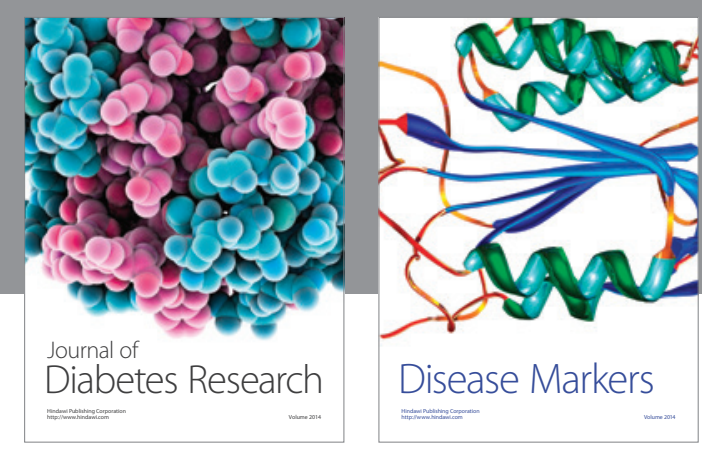

Disease Markers
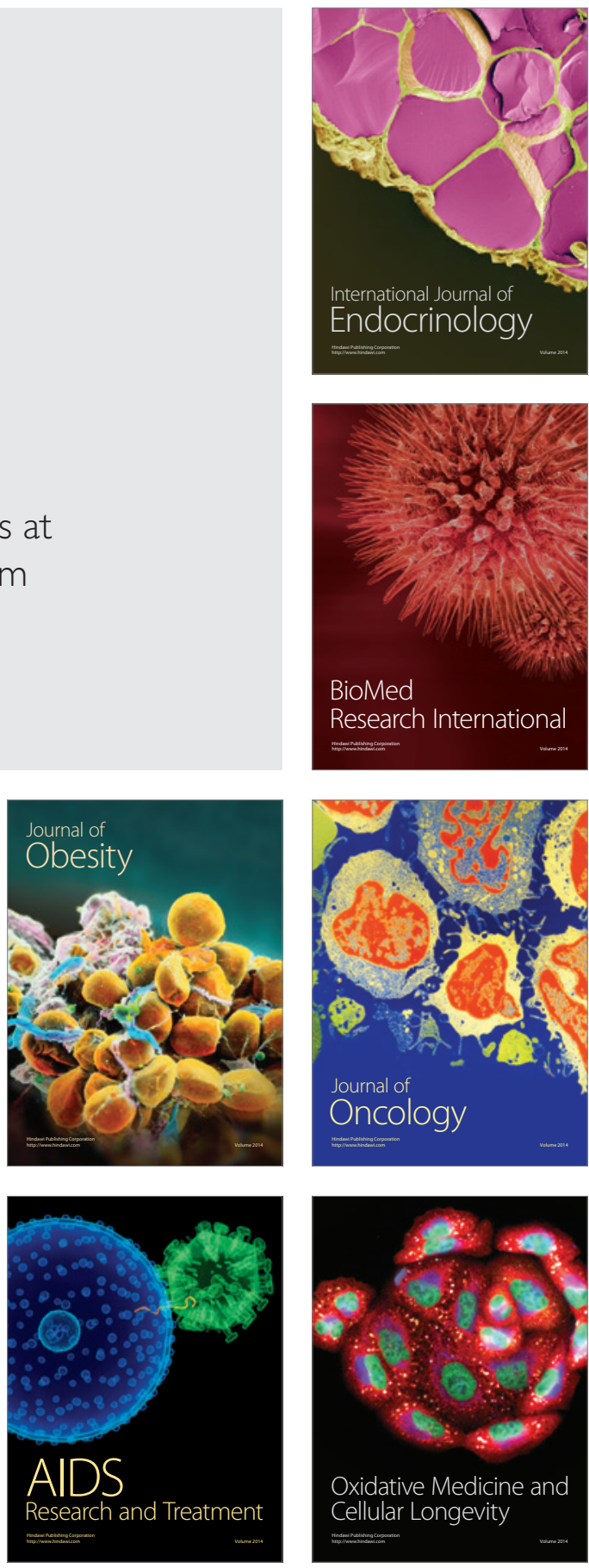